\title{
كلمة التحرير
}

\section{حاجة الأمة إلى القيادة العلمية والفكرية}

\section{هيئة التحرير}

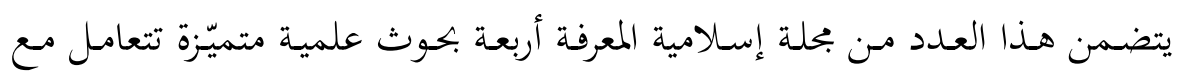
موضوع المقاصد، بوصفه عاملاً فاعلاً في الاجتهاد الفقهي، وشمول تطبيقاته لمسائل العلم

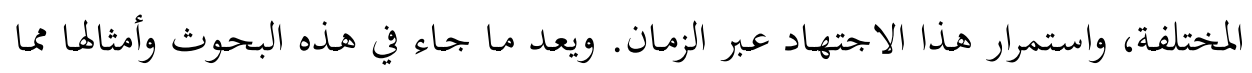

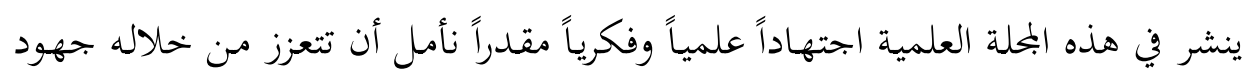

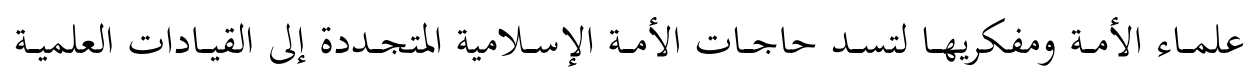

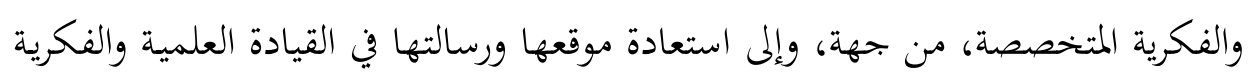
في العالم، من جهة أخرى.

إنّ العلوم كلَّها هي نتاج الإدراك والفكر البشري، سواءً كان مصدرها الوحي الإلهي

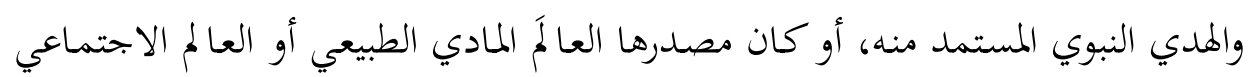

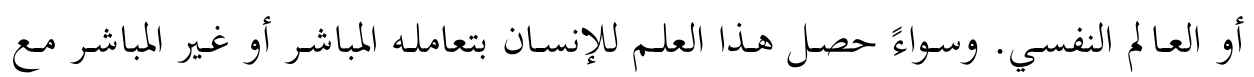
النصوص والأشياء والأحداث والظواهر، أو عن طريق النظر والتفكر العقلي، أو المشاهدة الحسية والتجربة العملية.

لذلك فإنّ العلوم -عند الإنسان- كلها هي فكر إنساني. لكن هذا الفكر حصل

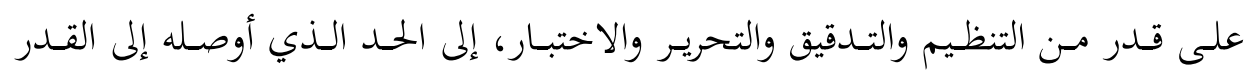

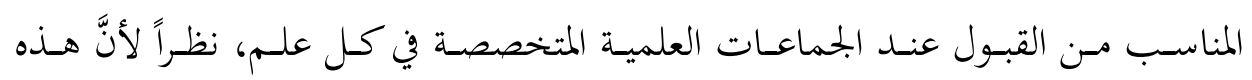
الجماعات/القيادات العلمية هي المرجعية في تحديد ما يدخل في العلم وما لا يدخل فيه. أمسا الفكر فنقصد به في مقامنا هذا نوعاً من الإدراك والفهم الذي ينطلق من قدرة الإنسان على استيعاب العلم وبحاوزه؛ أي الخخروج من تفاصيله الجزئية إلى رؤيته الكلية،

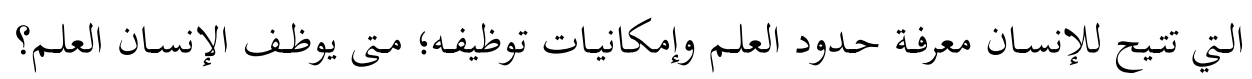


ولماذا يوظفه؟ وكيف يوظفه؟ إلخ. وينظر الفكر في خحارج حدود العلم ليستشرف الآفاق

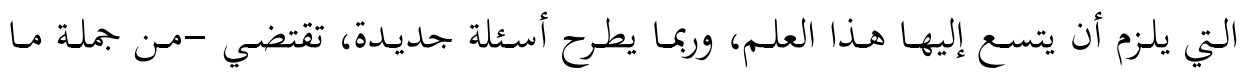

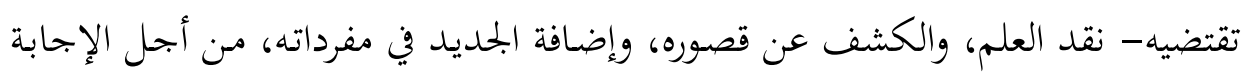

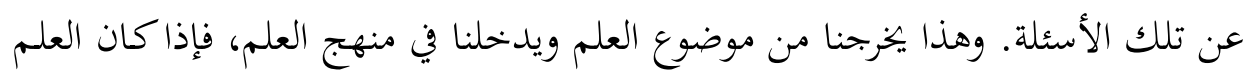

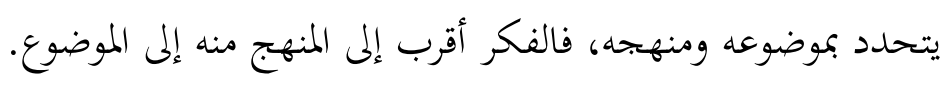

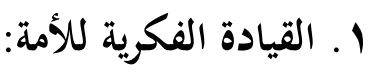

الأمة الإسلامية حاملة الرسالة الإلهية الخاتمة، ووريثة القيادة النبوية الراشدة، ومصادر

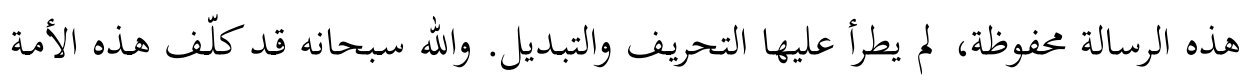

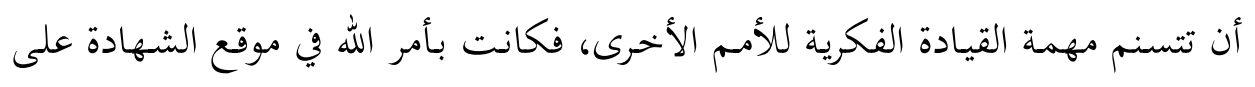

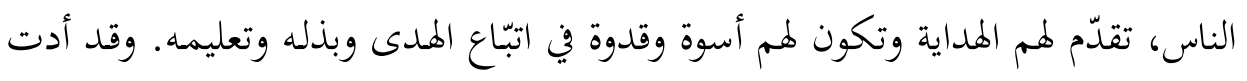

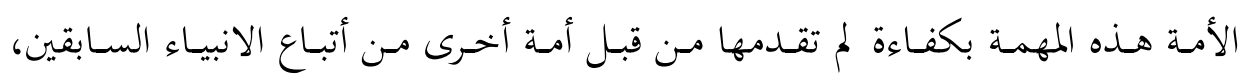

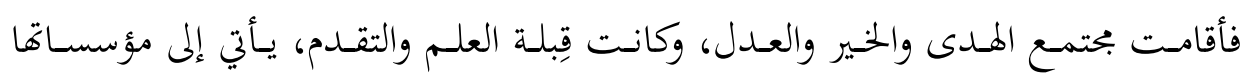

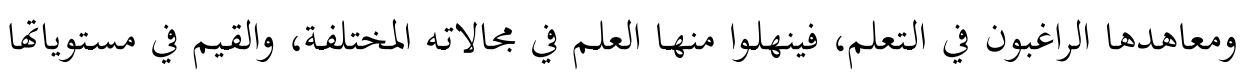

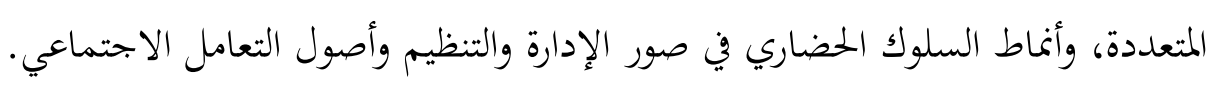

\section{Y. قيادات فكرية متخصصة:}

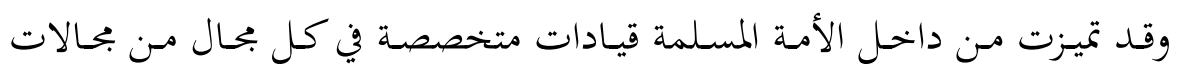

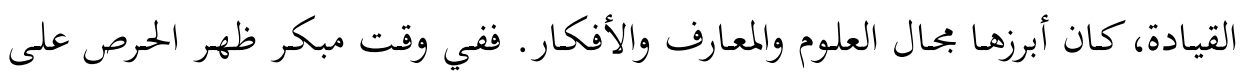

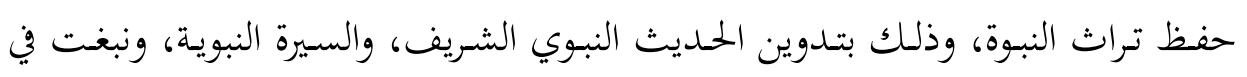

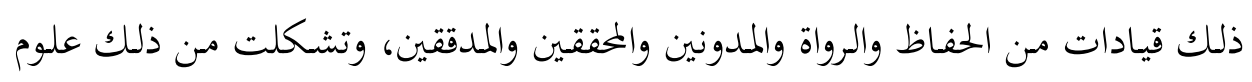

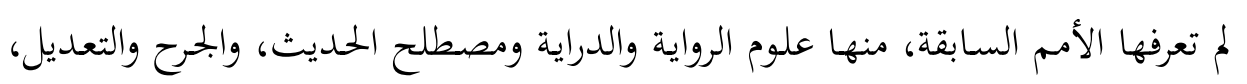

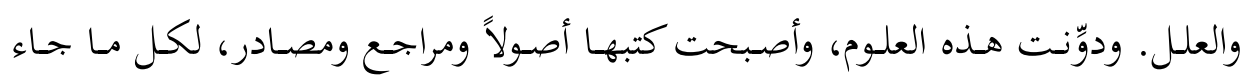
بعدها من تطور ونبوغ. و ودون. 
وأصبح علماء الحديث قيادة فكرية لمدرسة من مدارس الفكر الإسلامي، تميز فيها

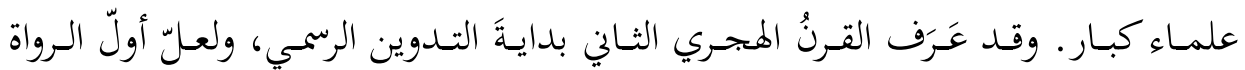
المدونين محمد بن مسلم الزهري، ثم ابن جريج، وابن إسحاق، ومالك بن أنس، ومماد،

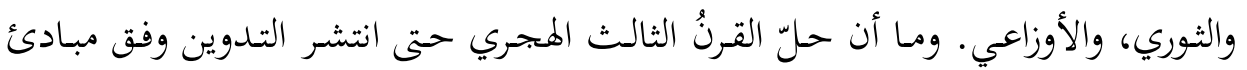
معلومة في التوثيق والتصنيف، فصنف الإمام أحمد بن حنبل مسنده، وصنف وإسحق بن راهويه مسنداً آخر، ثمُ كُتب صحيحُ البخاري وصحيحُ مسلم، وسنن الترمذي والنسائي وابن ماجة وأبي دواد.

ومثل ذلك يقال عن قيادات فكرية أخرى تميزت في أبواب تصنيف الأحكام الفقهية الشرعية، وضمن مناهج محددة، فعرفت المدرسة الفقهية قيادت فذة في علوم الفقه، منها

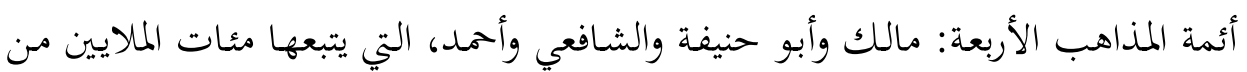

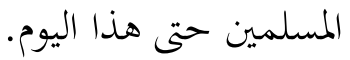

والأمر نفسه يقال حول مدارس التفسير، والعقيدة، والكلام، والتصوف، وغير ذلك من المحالات التي عرف في كل منها قيادات فكرية توزعت طوائف الأمة على اتباعها. ولم يقتصر تشـُّل القيـادات الفكريـة على العلوم الدينية المشـار إليها، بـل ظهرت كذلك قيادات في علوم الطب، والفلك والبصريات والكيمياء والفلاحة، وغير ذلك. وممن عرف في الطب مثلاً الشيخ الرئيس ابن سينا صاحب كتاب القانون في الطب، وأبو

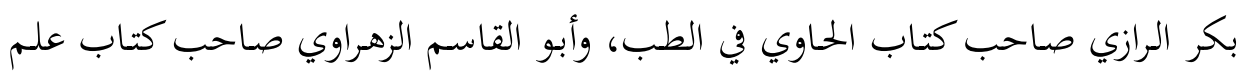
الجراحـة المسـمى التصريف لمن عجز عن التأليف، وغير ذلك كثير. وفي كل علم مـن

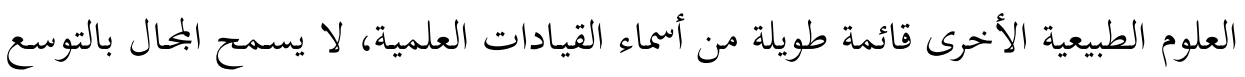
في ذكرها.

\section{ب. المؤسسات والقيادة الفكرية:}

وكان المسجد في بداية الأمر هو المؤسسة التي تنمو فيها كفاءات العلماء وخبراقم،

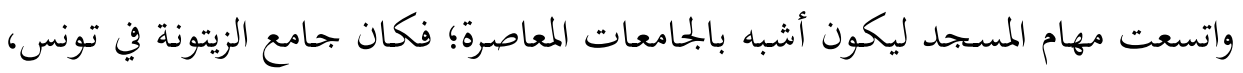




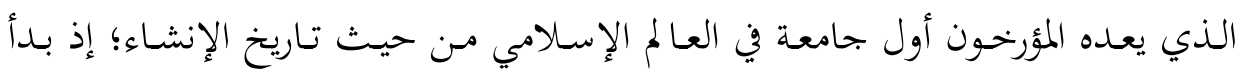

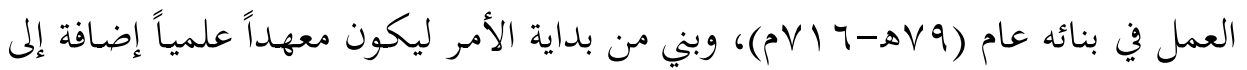

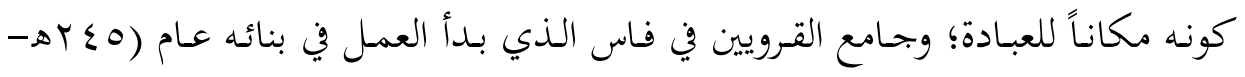

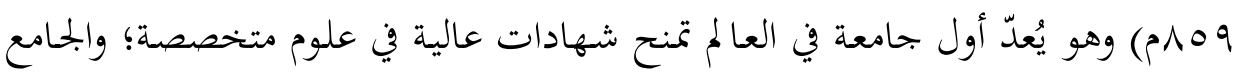

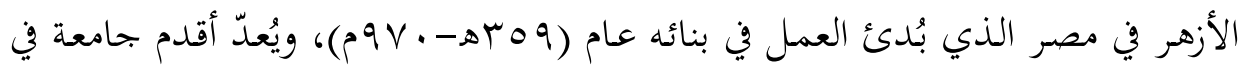

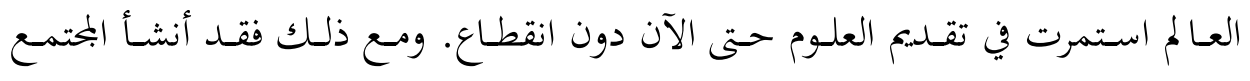

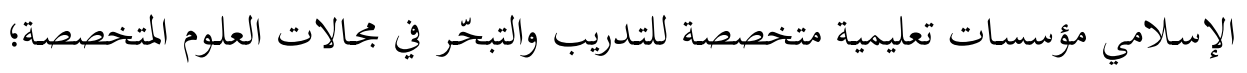

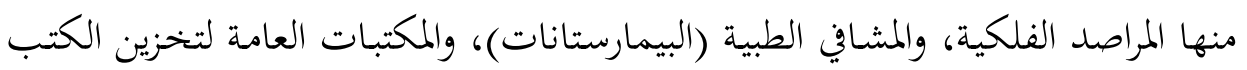
ونسخها وترجمتها، مثل بيت الحكمة في بغداد ودار الحكمة في القاهرة.

\section{ع. النخب الفكرية أساس نهضة أوروبا:}

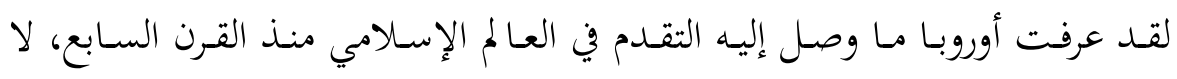

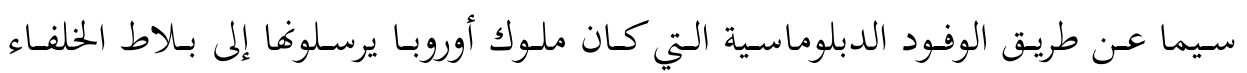

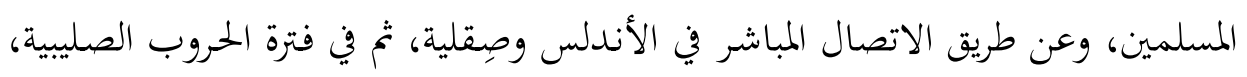

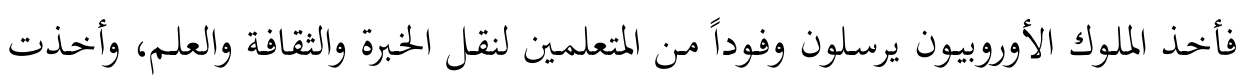

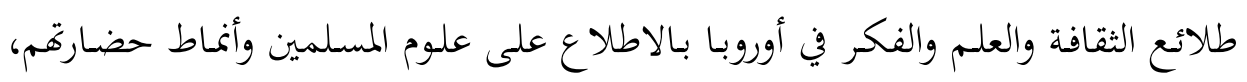

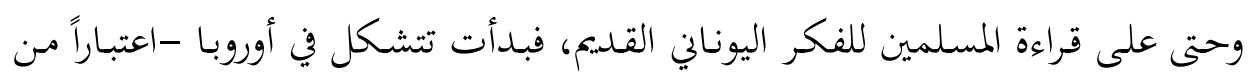

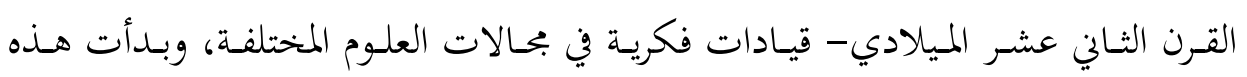

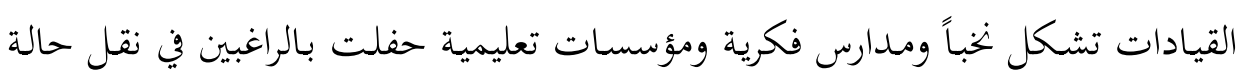

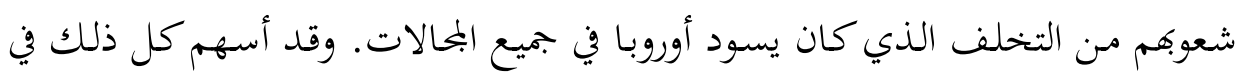

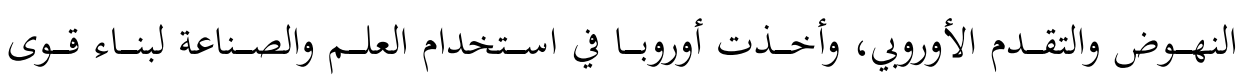

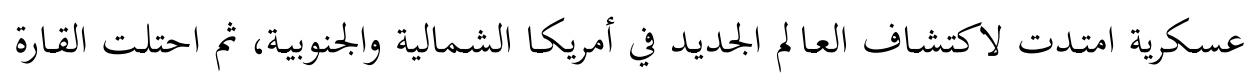

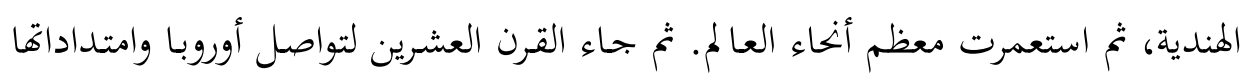
في أمريكا الشمالية تقدّمها في حضارة جديدة غير مسبوقة. 


\section{هـ الإبداع الفردي أساس القيادة الفكرية:}

لقــ كـان كـل عـالم مـن هـؤلاء العلمـاء، في التخصصـات المختلفـة، يمثل في زمانـه ومكانه قيادة فكرية، وكان أهل التخصص في كل علم يمثلون نخباً من القيادات الفكرية

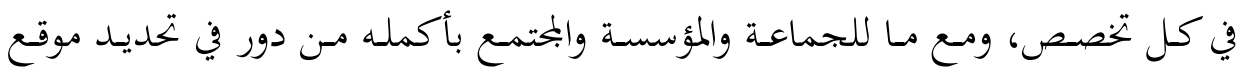
الفكر في قيادة المجتمع، فإننا لا نستطيع بحاهل دور الفرد في الإبداع العلمي والفكري. الفكر وفقق هـذا التحليل المبـين أعـلاه أقرب إلى الرؤى الإبداعيـة، التجديديـة، أو

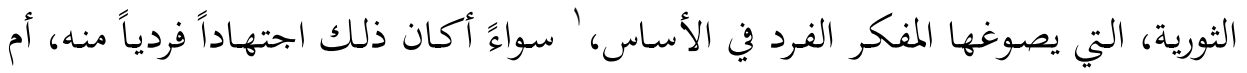
صياغةً لنتيجة الحموار والنقاش والبحث مع آخرين. وربما تتوالى الأفكار في حقل علمي

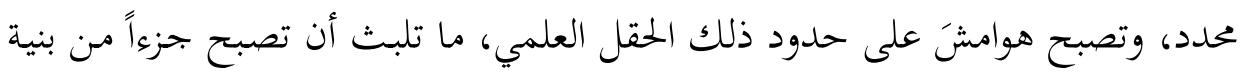
العلم، عندما تقبلها الجماعة العلمية المتخصصة، وتعتمدها عنصراً أساسياً في تلك البنية.

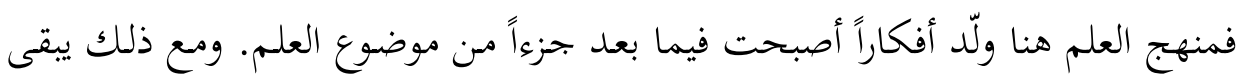

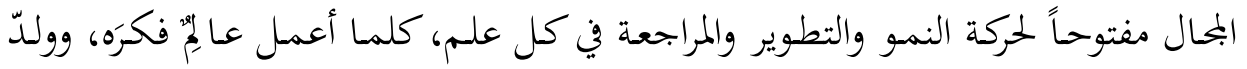

$$
\text { الجديد من الفكر العلمي في تخصصه. }
$$

لكـن الإنجـاز في الفكـر البشـري لا يقتصـر على بجـال واحسـ مـن بجـالات العلـوم

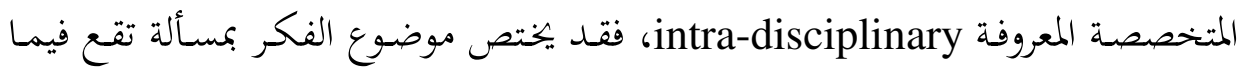

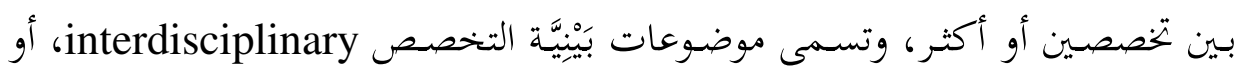

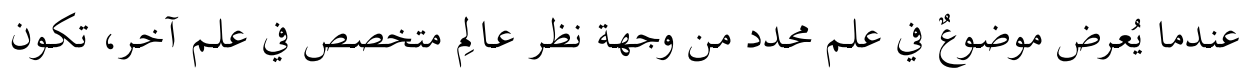

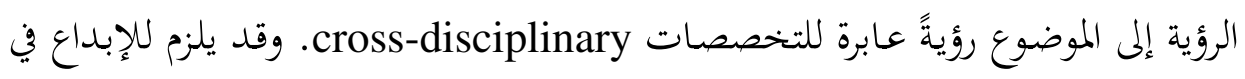

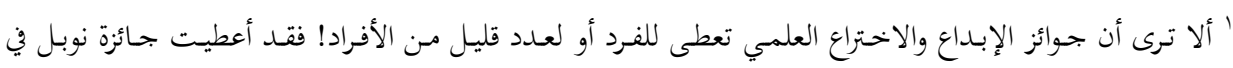

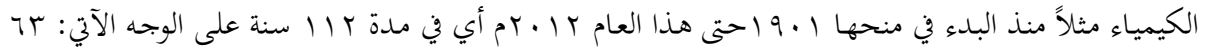

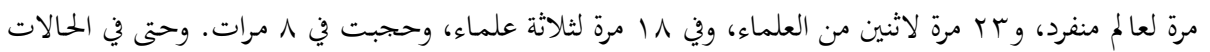

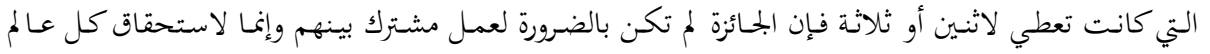

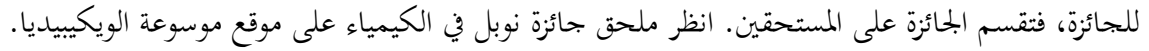

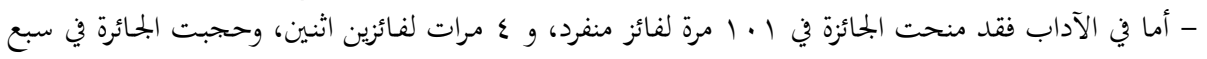
مرات. انظر: موقع موسوعة الويكيبيديا. 


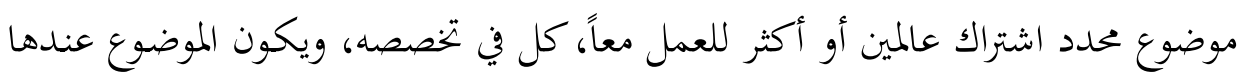

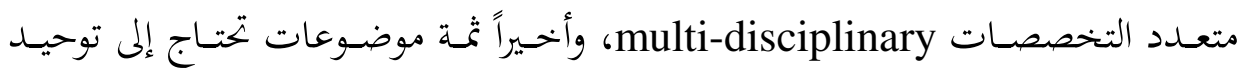

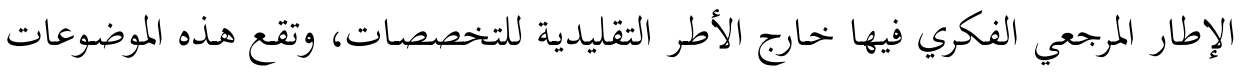

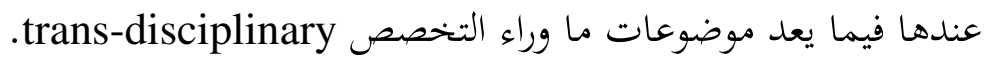

وفي كثير من الحالات لا يصنف الإبداع الفكري في بحال علمي متخصص، وإنما

$$
\text { يصنف في بحال من بحالات الفنون. }
$$

وإذا كان العلم يهتم بالموضوع من حيث هو، وينشغل في بيان عناصره وجزئياته وتنظيم ما يتوفر عنه من معلومات ومعارف تفصيلية، فإن اهتمام الفكر ينصب على

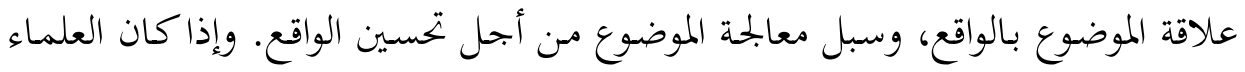

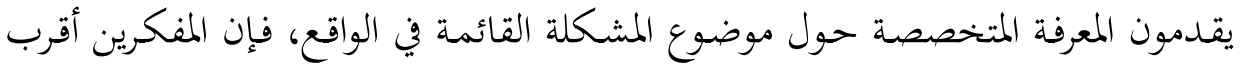

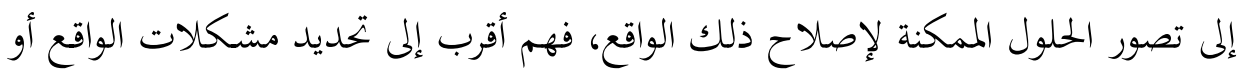

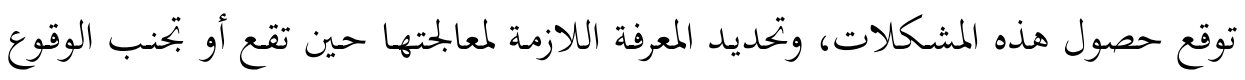

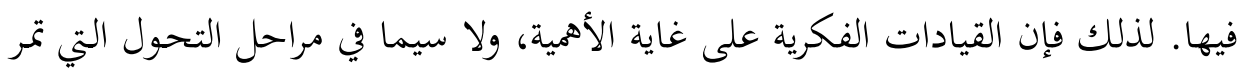

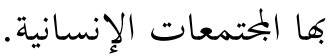

\section{7. الجامعة في موقع القيادة الفكرية للمجتمع:}

حصل تطور كبير على مفهوم الجامعة ومهمتها في البحتمع الإنساني، عبر التاريخ.

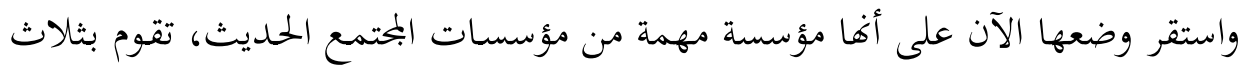

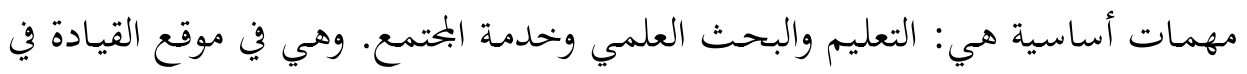

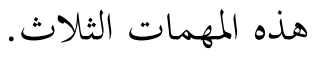

ففي التعليم استقر النظام الجحامعي على التمييز في بحـالات المعرفة الإنسـانية في

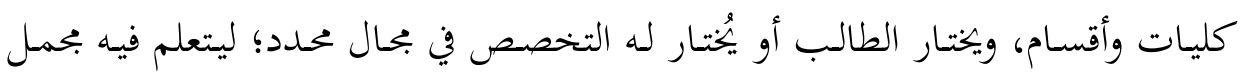

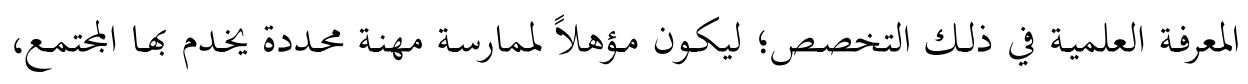


عندما يكمل المستوى الأول من التعليم، فيما تتطلبة الدرجة الجحامعية الأولى (الإجازة، أو البكـالوريوس أو الليسـانس). وإذا أراد مواصـلة التعلـيم فعليـهـ أن يختـار فرعـاً مـن فـروع تخصصه، ويتعلم أصول البحث فيه، ويتدرب على البحث في مسألة محددة مـ مسائل ذلك الفرع، وينجز بحثاً حول تلك المسألة. وبذلك يكون قد استكمل متطلبات الدرجة الجامعية الثانية (الماجستير). فيغدو بـلك أقدر على ممارسة مهنته وتحديد مشكلاتها، وربما يتسنم بعض مسؤوليات القيادة في مسائل تلك المهنة. وإذا أراد أن يواصل التعليم، في تخصصه، فعليه أن يدخل في جزئيات موضوع التخصص، ويتبحر في معرفة ما قادت إليه المعرفـة الإنسـانية في ذلك الموضسوع، ويقـف على حـدود تلك المعرفة، ويتمكن مـن تقويمها ونقـدها ومعرفة مشكلاتما، والأسئلة التي لم يتم تقـديم إجابـات عليها، والآفاق

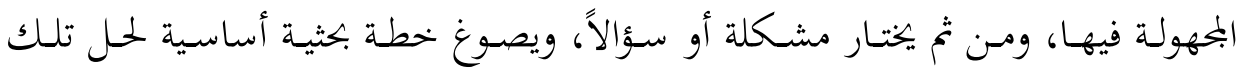
المشكلة أو الإجابة على ذلك السؤال. وتكون نتائج بحثه قفزة على حدود العلم، وإضافة حقيقيـة إليـه. وعنـدها لا تكـون خحمتـهـ لتطبيقـات المعرفـة المتخصصـة في مهنـة محسدة مقصورة على بحتمعه المحلي، وإنما هي خحدمة للمعرفة الإنسانية، ربما تخدم البشرية كلها، وبــلك تســكمل متطلبـات التعلـيم الجـامعي للحصـول على الدرجـة الجامعيـة الثالثـة (الدكتوراه). وأصبحت الجامعة، في بحال التعليم، في موقع القيادة في تأهيل الكوادر التي تخدم البحتمع في بحالات التخصص العلمي والعملي، وترقية هذه الكوادر، ورفع كفاءقا. أمـا وظيفة الجحامعة في بحال البحث العلمي، فبإن ذلك لا يتوقف على مـا يقوم بـه

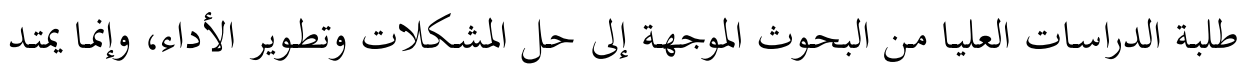
إلى البحوث التي يقوم بها أعضاء هيئة التدريس في الجامعة، التي يفترض أهما تخدم حركة

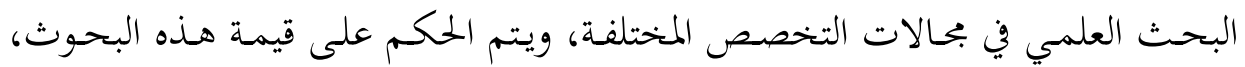
وتقويم صلاحيتها للقبول والنشر في البملات المتخصصة بالبحث، عن طريق شخصيات تمتلك من السلطة العلمية في بحال تخصصها ما يؤهلها لذلك الحكمبم. ولم يعد مقبولاً اليوم أن يكون البحث من أجل البحث، وإنما قيمة البحث هي في ما يمكن أن ينتج عنه اليوم 


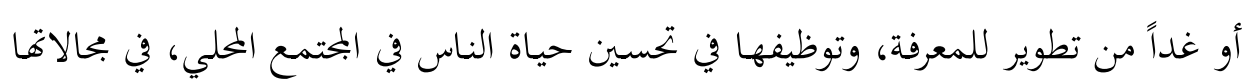
المختلفة، أو ترقية الحياة البشرية في البحتمع الإنساني بصورة عامة.

يضاف إلى ذلك أن الجامعة تنشئ مراكز متخصصة للبحث يعمل فيها باحثون

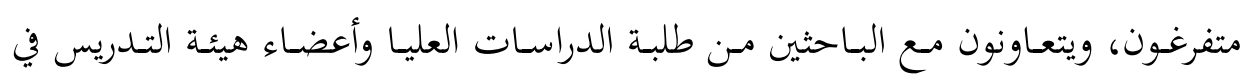

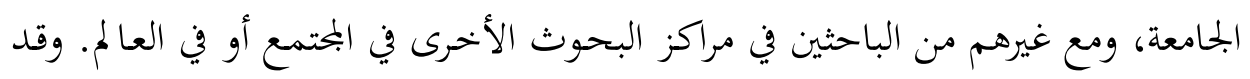

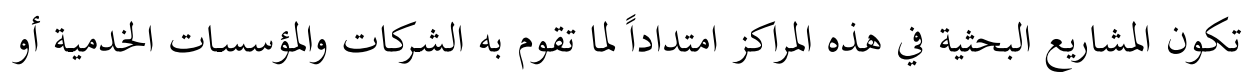

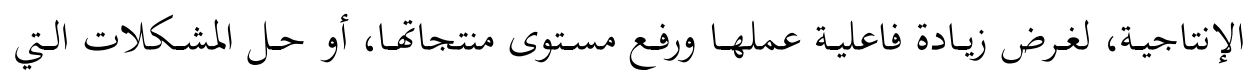
تواجهها، أو فتح آفاق جديدة وغير مسبوقة للخدمة أو الإنتاج.

ولا شكّّ في أن قيام الجحامعة بوظيفة البحث العلمي على الوجه المشار إليه هو مهمة

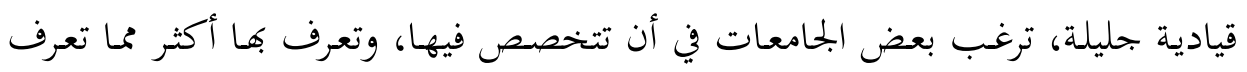

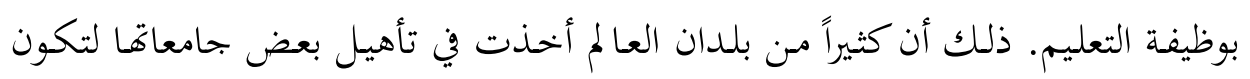

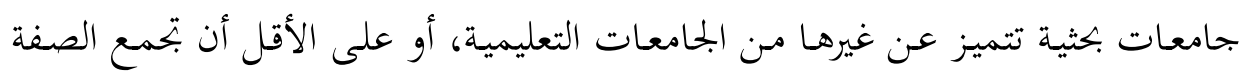

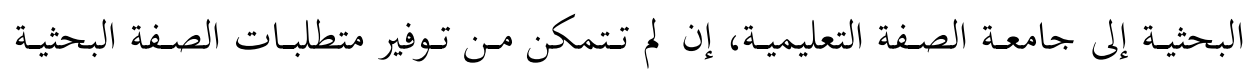

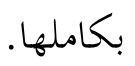

أمـا وظيفـة خدمة البحتمع، فإنَّ الجامعة لا تملك أن تقصر عملها على مـا سبقت

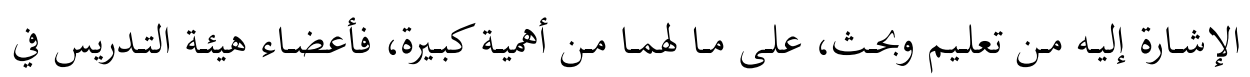

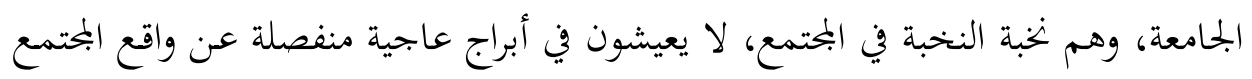

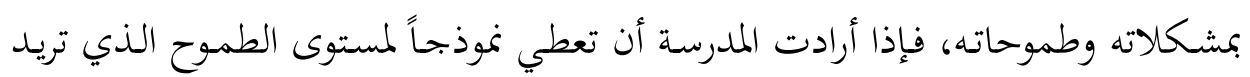

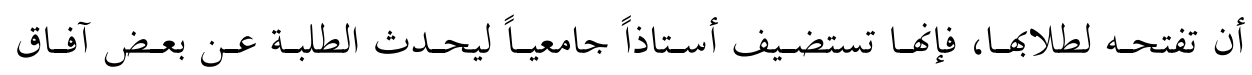

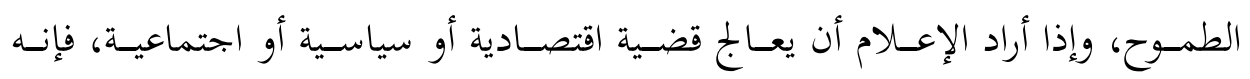

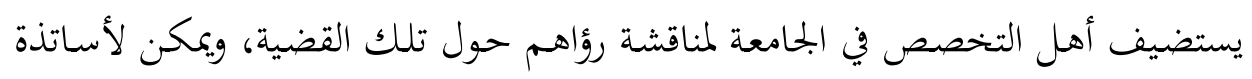

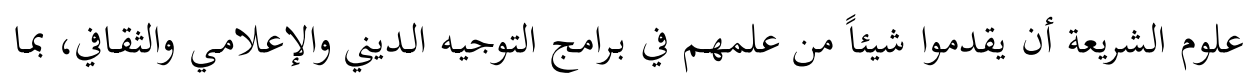
في ذلك خطبة الجمعة في المساجد، وهكذا. 
ثم إن أعضاء هيئة التدريس في الجحامعات هم أعضاء في أسرهم وعائلاقم وأحيائهم

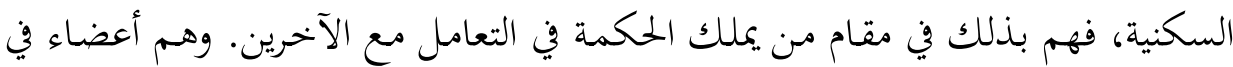

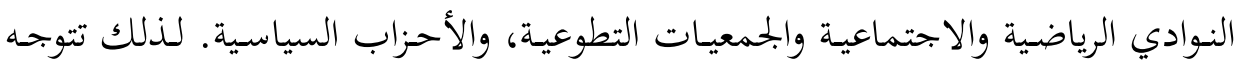
إليهم الأنظار لتقديم ما يملكون من خبرة ودراية، في فهم الأحداث التي تطرأ، وفي التعامل

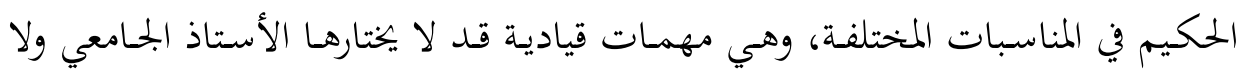
يسعى لها، لكنّ البحتمع من حوله يتوقعها فيه ويطلبها منه. وأخيراً فإنَّ من بين أعضاء هيئة التدريس من يعتصر خبرته وبحربته في العمل وفي الحياة، لتأليف كتب يقدمون فيها لعامة القراء فهمهم لموضوعات محددة يوظفون فيها

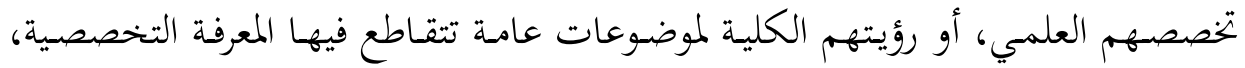
والخـبرة العمليـة، والبصـيرة الشخصـية، وتتضـمن اجتهـادات فكريـة، ربمـا تمثـل تأصسيلاً

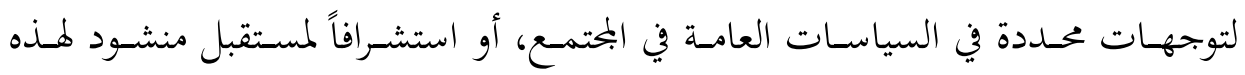

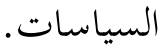

إنّ صور القيادة في الوظائف الثلاث للجامعة تتجاوز الصور التقليدية مـ الأداء

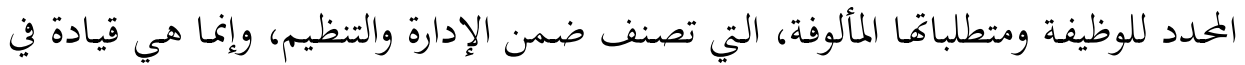

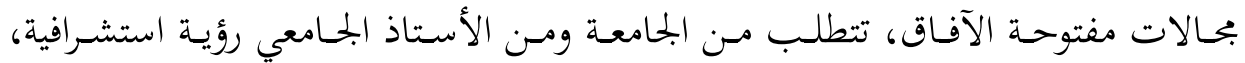
وإنتاجاً فكرياً على درجة عالية من الأهمية.

جاءت أبحاث هذا العدد الأربعة لتبرز موقع الاجتهاد في المنظومة التفكيرية في علوم

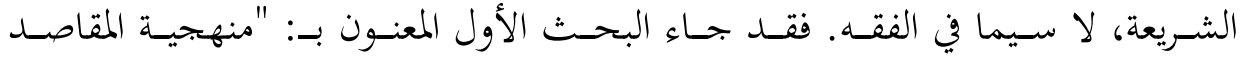
والوسائل في الاجتهاد الفقهي" للدكتور معتز الخطيب، ليكشف تاريخ المنهجية في العقل الماند

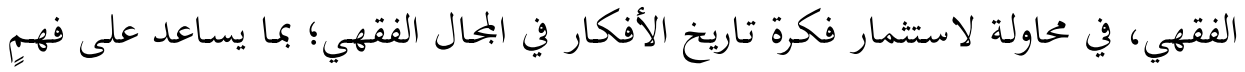

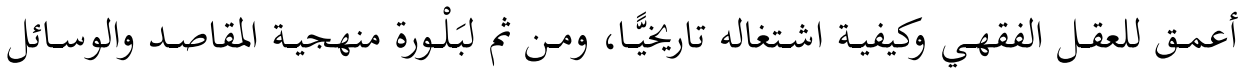

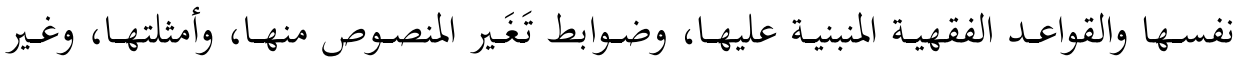


وحاول الدكتور جاسر عودة في بحثه المعنون بـ: "مدخل مقاصدي للاجتهاد: حلكُ

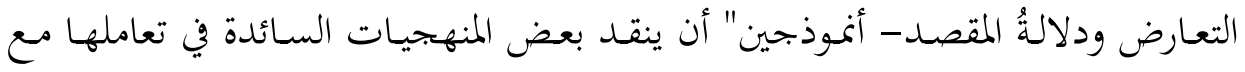

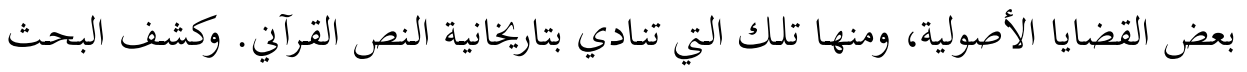

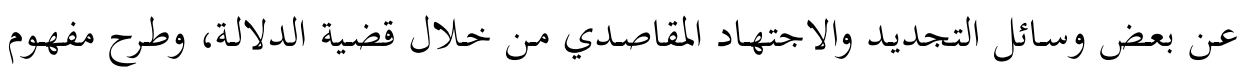

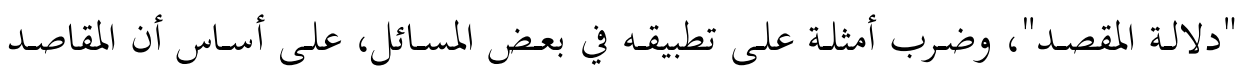

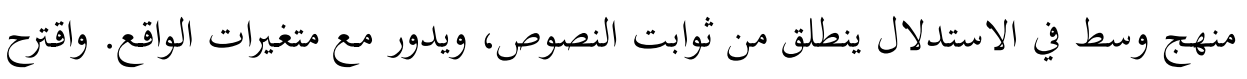

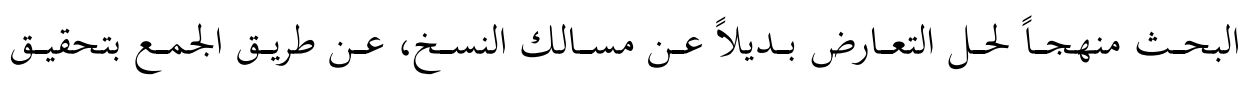
المقاصد على اختلاف الظروف، وذلك عن طريق فهم المقاصد النبوية بملاحظة المقاصد، واعتبار التنوع المقصود، واعتبار التدرج المقصود. أما البحث الثالث المعنون بـ: "التنسيق بين الكُلِّيات والجزئيات وأثره في الاجتهاد

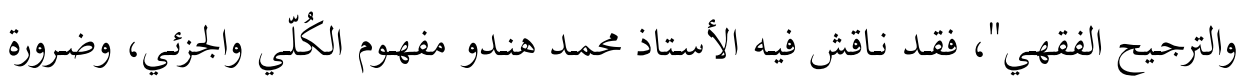

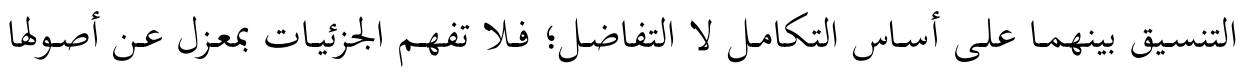

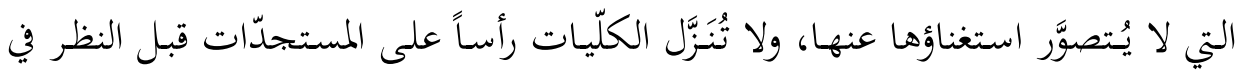

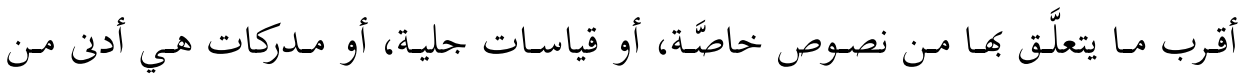

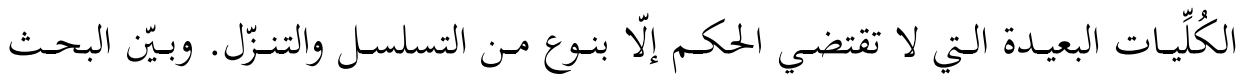

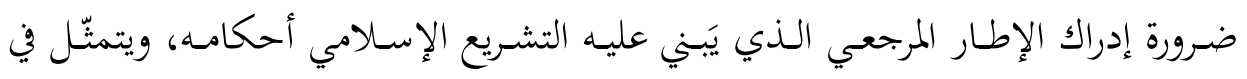

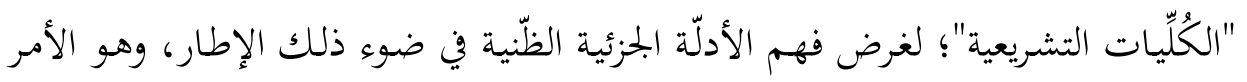

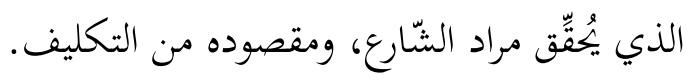
وناقش الدكتور أحمد غاوش موضوع "الاجتهاد الفقهي بين الانقطاع والاستمرار:

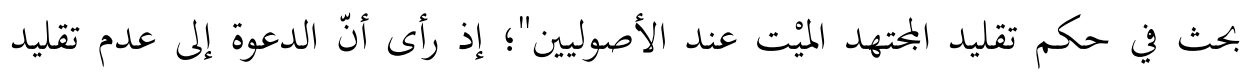

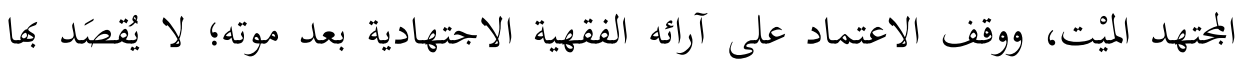

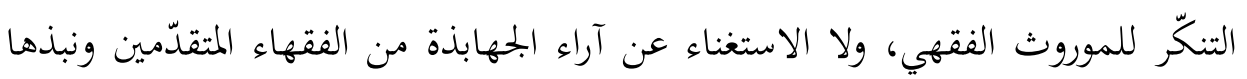

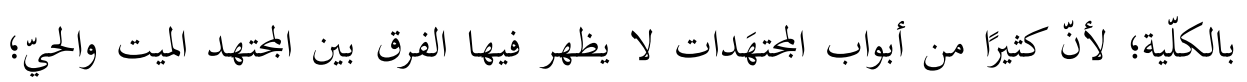


نظرًا لعدم ارتباطها بتغيّر الزمان والمكان والبيئات. وثمة حاجة للمجتهد الحي الذي ينظر في النوازل والمستجدات، منطلقاً من فهم دقيق للكتاب والسنة ومقصودهما. وقد تضمن هذا العدد من بحلة إسلامية المعرفة، إضافة إلى ما سبق، مقالة للدكتور

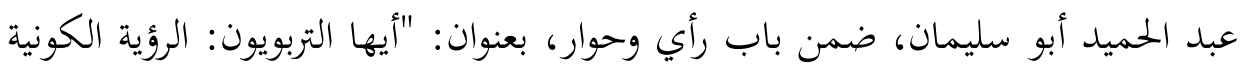
الحضارية القرآنية ثم التربية.. والتربية.. والتربية... العلمية".

واحتـوى العـدد قـراءتين: قـراءة لكتــاب "نظريــة التعليـل في الفكــين الكلامسي

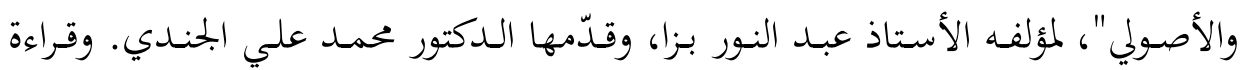

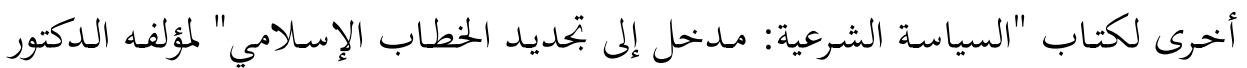
عبد الله إبراهيم زيد الكيلاني، وقدّمها الدكتور ماهر حسين حصوة.

وتم استعراض تقرير عن دورة علمية تدريبية عقدها مكتب المعهد في الأردن، وهي بعنوان: "منهجية التكامل المعرين". وفي العدد حلقة جديدة من عروض مختصرة لعدد من الكتب التي صدرت حديثاً، كما يتصل بموضوع الاجتهاد، قد يفيد منه بعض الباحثين. ودعوة للمشاركة في الكتابة، بعدد خاص، عن الإعلام في الرؤية الفكرية الإسلامية. نسأل الله أن ينفع بهذه الجهود. والحمد لله رب العالمين 